\title{
Neonatal hormone manipulations and the maintenance of perineal muscles and their motor neurones in Albino Swiss rats*
}

\author{
J. C. Currie, P. A. Houston $†$, A. Henderson and A. P. Payne \\ Department of Anatomy, University of Glasgow, Glasgow G12 8QQ,UK
}

\begin{abstract}
Summary. Newborn female Albino Swiss rats received testosterone propionate, dihydrotestosterone benzoate or oestradiol benzoate for 4 days after birth. The neonatal administration of all three hormones maintained neurones of the spinal nucleus of bulbocavernosus (SNB) complex in adulthood at levels intermediate between those found in normal females ( $\sim 40$ neurones) and those found in normal males ( $\sim 220$ neurones). Dihydrotestosterone benzoate was the most effective treatment. Oestradiol benzoate, while as potent as testosterone propionate in maintaining SNB neurone numbers, could not maintain the perineal muscles which are their normal target. Dihydrotestosterone benzoate and testosterone propionate maintained both neurones and muscles.

Newborn male Albino Swiss rats received either the aromatase inhibitor 4-OHandrostenedione, or the $5 \alpha$-reductase inhibitor aza-steroid $17 \beta-\mathrm{N}, \mathrm{N}$-diethylcarbamoyl4-methyl-4-aza-5 $\alpha$-androstan-3-one (4-MA). Only neonatal treatment with 4-MA led to reduced $\mathrm{SNB}$ neurone numbers in adulthood, but the reduction was modest $(-16 \%)$. The results of the two experiments suggest that several hormones can maintain SNB neurone numbers in Albino Swiss rats, but that $5 \alpha$-reduced metabolites of testosterone may be particularly effective.
\end{abstract}

Key'ords: neonate; motor neurones; hormones; perineal muscles; rat

\section{Introduction}

There are several regions of the mammalian central nervous system which exhibit morphological sex differences, e.g. the medial preoptic area, the anterior hypothalamus, the accessory olfactory bulb and the amygdala (Gorski et al. 1980; Nishizuka \& Arai, 1981; Bleier et al., 1982; Segovia et al., 1986). Differences range from the size of certain areas to the types of neurones and synaptic connections which occur within them. All differences appear to be established during the perinatal period and to depend on the hormonal environment at that time (Arnold \& Gorski, 1984).

One sexually dimorphic region within the spinal cord consists of a group of motor neurones which innervate perineal muscles implicated in penile erection and genital reflexes associated with cervical stimulation and copulatory plug formation (Breedlove, 1984). In rats, these neurones form the spinal nucleus of bulbocavernosus (SNB) which projects into the ventral white matter in segments L4-6 (Breedlove \& Arnold, 1981); the SNB is thought to be the counterpart of Onuf's nucleus in man, which occurs in the ventral grey horn of segments S2-4 (Forger \& Breedlove, 1986). In adult male rats, the SNB consists of some 5 times more neurones than in the female. Moreover, in adult female rats, the perineal muscles (which are conspicuous in the male) are absent;

*Reprint requests to Dr A. P. Payne.

†Present address: Department of Anatomy, University of Oxford, Oxford OX13QX, UK. 
they are said to involute soon after birth unless androgens are present (Cihák et al., 1970; Arnold, 1984).

In mammalian brain dimorphisms, the male pattern depends on the presence of aromatizable androgens or oestrogen during the critical perinatal period (Arnold \& Gorski, 1984; Tobet et al., 1986). The case of SNB neurone maintenance (which has been studied extensively in SpragueDawley rats) appears more complex. While perinatal testosterone maintains both SNB neurone numbers and perineal muscles, oestradiol appears to be ineffective (Breedlove et al., 1982). Dihydrotestosterone has been variously reported to maintain SNB neurones (Breedlove \& Arnold, 1983; Arnold, 1984), or not to maintain SNB neurones but to maintain extra neurones in other parts of the lumbar ventral grey horn such as the dorsolateral nucleus (DLN) (Kurz et al., 1986; Sengelaub et al., 1989). Differences may be due to the timing of DHT administration (pre- or postnatal) or dosage. This requires resolution, since it has been suggested that development of the SNB could form an important model for the role of hormones in neurogenesis, cell death and migration (Sengelaub, 1989). The present study was conducted on a different strain of rats (Albino Swiss) to see whether any of these findings could be confirmed and to extend them. Two experiments were performed to examine SNB neurone counts in (1) females treated perinatally with testosterone, dihydrotestosterone or oestradiol; and (2) males treated perinatally with aromatase or $5 \alpha$-reductase inhibitors.

\section{Experiment 1}

\section{Materials and methods}

Female Albino Swiss rat pups received, on Days I- 4 after birth, either testosterone propionate $(200 \mu \mathrm{g} /$ day s.c., $\mathrm{N}=10)$, $5 \alpha$-dihydrotestosterone benzoate (DHTB, $200 \mu \mathrm{g} /$ day s.c., $\mathrm{N}=10)$, or oestradiol benzoate $(20 \mu \mathrm{g} /$ day s.c., $\mathrm{N}=8)$. All hormones were injected in arachis oil $(0 \cdot 1 \mathrm{ml})$ and control females $(\mathrm{N}=7)$ received oil vehicle alone. As adults (3-4 months), all females received testosterone propionate for I month (500 $\mu \mathrm{g}, 3$ times/week s.c.) to (i) enhance the size and staining properties (but not the number) of SNB neurones (Arnold, 1984) and (ii) to increase the size of the perineal muscle fibres, thus making the muscles (if present) readily identifiable (Venable, 1966).

All females were killed at the end of the period of testosterone treatment with an overdose of pentobarbitone sodium, and perfused with $500 \mathrm{ml}$ buffered $10 \%$ formaldehyde. The lower part of the spinal cord was removed and stored in buffered $10 \%$ formaldehyde before sectioning at $100 \mu \mathrm{m}$ on a Bio-rad micro-cut $\mathrm{H} 1200$ vibratome and staining with $0.4 \%$ thionine in alcohol and acetic acid $(\mathrm{pH} 4.5)$. All sections with SNB neurones were examined and the number of neurones counted (see Fig. 1). Only those neurones in which a nucleolus could be seen were included, and no correction for cell size was made. The perineal muscles, if present, were dissected out and weighed together with the phallus (see Fig. 2). SNB neurone counts were compared for the groups using one-way analyses of variance (F) followed by Least Significant Difference analysis (Statistical Graphics System; Statistical Graphics Corporation) to reveal inter-group differences. Perineal muscles were only found in two groups, and weights were compared by Student's $t$ test.

\section{Results}

As shown in Table 1, there were differences in numbers of SNB neurones in the 4 groups (F $=43.85$, d.f. $3,31, P<0.001$ ). All three experimental groups had significantly more SNB neurones that did control females (for all, $P<0.01$ ), while DHTB-treated females had more neurones than did the other two experimental groups $(P<0.01)$.

No morphologically identifiable perineal muscles could be found in control female rats, or in those which had received perinatal oestradiol. By contrast, female rats which had received perinatal androgen had readily identifiable muscles. In females which had received testosterone, the perineal muscle complex and phallus were slightly heavier than in females which had received DHTB $(t=3.71$, d.f. $14, P<0.05)$. 


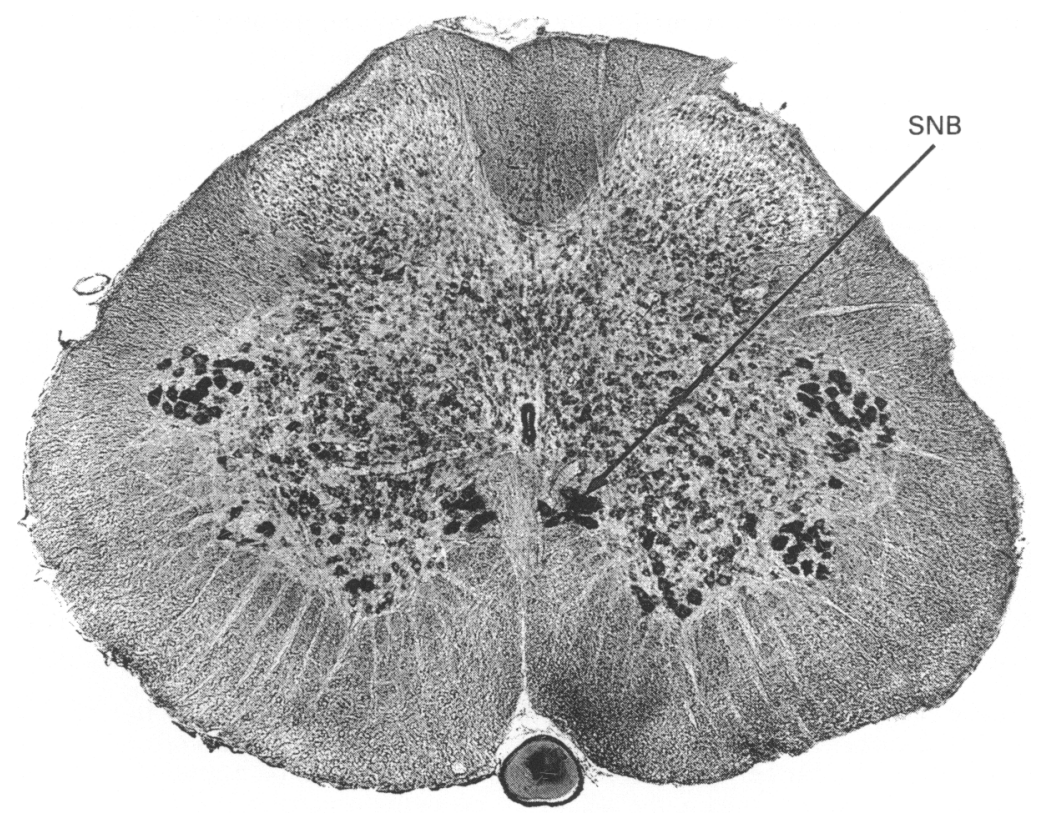

Fig. 1. A transverse section $(100 \mu \mathrm{m})$ through the spinal cord of a male rat at segment $\mathrm{L} 5$. The motor neurones forming the spinal nucleus of bulbocavernosus (SNB) are indicated. Stained with thionine, $\times 40$.

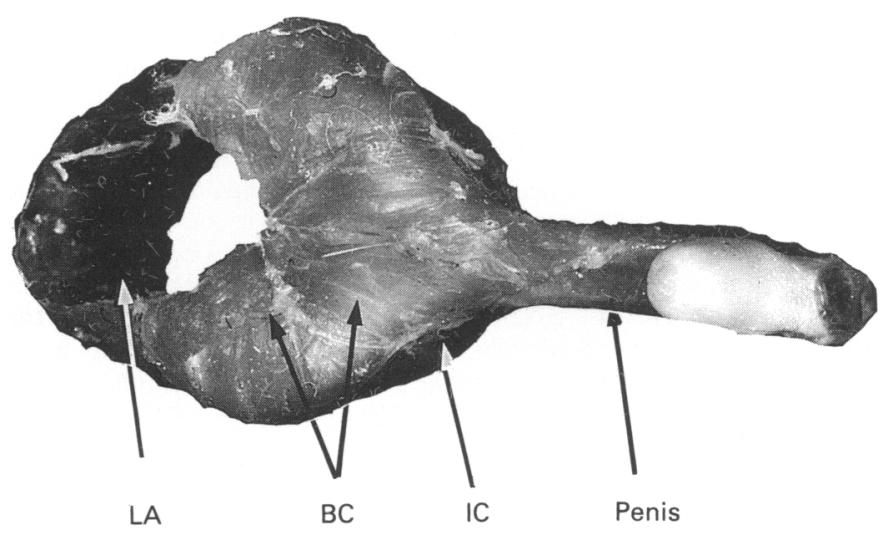

Fig. 2. The penis and associated perineal muscles of a male rat, showing ischiocavernosus (IC), bulbocavernosus (BC) and levator ani (LA). The last two muscles are normally innervated by SNB neurones. The anal canal has been removed from its position between LA and $\mathrm{BC} . \times 2 \cdot 5$.

\section{Experiment 2}

\section{Materials and methods}

In view of the results obtained in Exp. 1, male rats received, on Days 1-4 after birth, either (i) the aromatase inhibitor 4-hydroxyandrostenedione (4-OH-A (Sigma, Poole, Dorset, UK), $50 \mathrm{mg} / \mathrm{kg} /$ day s.c., $\mathrm{N}=9$ ) or (ii) the $5 \alpha$ reductase inhibitor 17ß-N,N-diethylcarbamoyl-4-methyl-4-aza-5 $\alpha$-androstan-3-one (4-MA, (Merck Sharp \& Dohme, Rahway, NJ, USA), $50 \mathrm{mg} / \mathrm{kg} /$ day s.c., $\mathrm{N}=12$ ). Treatment with $4-\mathrm{OH}-\mathrm{A}$ prevents the aromatization of testosterone 
Table 1. The number of SNB motor neurones and the relative weight of the perineal muscle complex in female rats which had received perinatally (daily on Days 1-4 after birth) arachis oil, testosterone propionate (TP), $5 \alpha$-dihydrotestosterone benzoate

(DHTB) or oestradiol benzoate (OB)

\begin{tabular}{lccc}
\hline Treatment & $\begin{array}{c}\text { No. of } \\
\text { rats }\end{array}$ & $\begin{array}{c}\text { SNB } \\
\text { neurones }\end{array}$ & $\begin{array}{c}\text { Perineal } \\
\text { muscle wt } \\
(\mathrm{g} / 100 \mathrm{~g})\end{array}$ \\
\hline $\begin{array}{l}\text { Oil } \\
\text { TP }\end{array}$ & 7 & $38 \pm 3$ & Absent \\
$(200 \mu \mathrm{g} /$ day $)$ & 10 & $103 \pm 4$ & $0 \cdot 17 \pm 0 \cdot 01$ \\
$\begin{array}{l}\mathrm{DHTB} \\
(200 \mu \mathrm{g} / \text { day })\end{array}$ & 10 & $142 \pm 10$ & $0 \cdot 14 \pm 0.01$ \\
$\begin{array}{l}\text { OB } \\
(20 \mu \mathrm{g} / \text { day })\end{array}$ & 8 & $99 \pm 9$ & Absent \\
\hline
\end{tabular}

Values are means \pm s.e.m.

to oestradiol (Brodie et al., 1977; Marsh et al., 1985), while 4-MA prevents the $5 \alpha$-reduction of testosterone to DHT (Liang \& Heiss, 1981; Liang et al., 1983). Each inhibitor was administered in arachis oil and control males $(\mathrm{N}=10)$ received oil vehicle alone. No further treatment was given and, as adults (4-5 months), all animals were killed, perfused and dissected as in Exp. 1. Again, the weights of the perineal muscles and phallus were recorded and the lumbar part of the spinal cord removed, sectioned and stained, and the number of SNB neurones counted.

\section{Results}

As shown in Table 2, there was a significant variance in SNB neurone numbers over the three groups of males ( $\mathrm{F}=3.46$, d.f. $2,28, P<0.05$ ). Males treated neonatally with 4-OH-A did not differ from controls, but males treated with 4-MA did $(P<0.05)$. Although statistically significant, the reduction in SNB neurone numbers $(-16 \%)$ was modest in absolute terms. The body weights of the adult male rats did not differ between the three groups, nor did the relative weights of testes, seminal vesicles, the block consisting of the phallus and perineal muscles, nor individual perineal muscles when dissected out.

Table 2. The number of SNB motor neurones, together with reproductive tract and perineal muscle weights, in adult male rats which had received perinatally on Days $1-4$ after birth arachis oil, the $5 \alpha$-reductase inhibitor 4-MA or the aromatase inhibitor 4-OH-A

\begin{tabular}{|c|c|c|c|}
\hline & \multicolumn{3}{|c|}{ Treatment } \\
\hline & Oil & 4-MA* & $4-\mathrm{OH}-\mathrm{A}^{*}$ \\
\hline No. of rats & 10 & 12 & 9 \\
\hline SNB neurones & $228 \pm 5$ & $190 \pm 7$ & $204 \pm 11$ \\
\hline Body weight $(\mathrm{g})$ & $322 \pm 15$ & $314 \pm 8$ & $288 \pm 14$ \\
\hline Relative weights $(\mathrm{g} / 100 \mathrm{~g})$ of & & & \\
\hline Testes & $0.78 \pm 0.03$ & $0.82 \pm 0.02$ & $0.85 \pm 0.05$ \\
\hline Seminal vesicles & $0.30 \pm 0.04$ & $0.26 \pm 0.02$ & $0 \cdot 26 \pm 0.02$ \\
\hline Perineal ms + phallus & $0.43 \pm 0.03$ & $0.41 \pm 0.03$ & $0.40 \pm 0.02$ \\
\hline Levator ani & $0.09 \pm 0.01$ & $0.09 \pm 0.0 \mathrm{I}$ & $0.09 \pm 0.01$ \\
\hline Bulbocavernosus & $0.21 \pm 0.02$ & $0.19 \pm 0.01$ & $0 \cdot 18 \pm 0.03$ \\
\hline Ischiocavernosus & $0.08 \pm 0.01$ & $0.07 \pm 0.0 \mathrm{I}$ & $0.07 \pm 0.01$ \\
\hline
\end{tabular}

Values are means \pm s.e.m.

*50 mg/kg/day. 


\section{Discussion}

The present two experiments confirm that a structural sex difference occurs in the lumbar part of the rat spinal cord. Normal adult males have over 200 motor neurones which form the spinal nucleus of bulbocavernosus (SNB), while females have approximately a fifth of this number. The present experiments also confirm that the administration of androgens (and, in the present experiment, oestradiol) to females during the perinatal period results in the maintenance of higher numbers of SNB neurones than in control females. All three hormones used were capable of significantly increasing SNB numbers when given perinatally. Testosterone and oestradiol appeared equipotent, while dihydrotestosterone resulted in the greatest increase. The results obtained here are at variance with those of Breedlove et al. (1982), who reported that oestradiol could not maintain SNB neurone numbers; in that study, treatment was given only on Day 2 after birth, but the dose of oestradiol benzoate used was much greater than in the present study. Hall et al. (1987) have shown that post-natal oestradiol (while not increasing their number) does increase the size of SNB cell bodies in adult female rats. Some studies using Sprague-Dawley rats suggest that perinatal DHT administration can maintain SNB numbers (e.g. Breedlove \& Arnold, 1983; Arnold, 1984) while others do not (e.g. Sengelaub et al., 1989). Discrepancies may be due to timing (post-natal administration more effective than pre-natal) or dosage; when DHT has been effective it has not been as effective as testosterone (e.g. Arnold \& Gorski, 1984). In the present study (involving Albino Swiss rats), DHT was the most effective of the treatments given and this may suggest strain differences in development of the SNB complex. For example, strain differences in SNB neurone numbers have been reported for mice (Wee \& Clemens, 1986) and there are even some mouse strains in which the numbers of neurones are decreased by castration in adulthood (Wee \& Clemens, 1987), a phenomenon which has not been described for the rat (see Breedlove \& Arnold, 1981).

In the second experiment performed here, newborn male rats were given inhibitors of aromatase or $5 \alpha$-reductase. Only 4-MA (which inhibits conversion of testosterone to $5 \alpha$-dihydrotestosterone (Brodie et al., 1977; Marsh et al., 1985) produced a significant reduction in SNB neurone numbers. Moreover, even though significant, the actual reduction was modest $(-16 \%)$. This suggests that, while androgens are necessary for the maintenance of SNB neurone numbers in Albino Swiss rats, and while, in normal development, one particular steroid hormone may be responsible for maintenance, under experimental conditions it appears that no one steroid is crucial. Furthermore, one difficulty of interpreting these data is that any reduction in conversion presumably increased the amount of testosterone itself or the amount available for conversion to other metabolites such as oestradiol. Nevertheless, Exp. 2 appears to complement Exp. 1 in that it suggests that $5 \alpha$-reduced metabolites of testosterone are particularly effective in maintaining SNB neurone numbers.

Comparing the two experiments performed here, no steroid treatment given to females was able to raise SNB neurone numbers to levels in males. The reason for this is not known, but it may be that the particular doses of hormones (or times of administration) used did not permit presumptive SNB neurones to reach their definitive position (see Sengelaub, 1989). An additional consideration is that, in both experiments, perinatal treatments were administered to gonadally intact animals. While it is possible that such treatments could result in longer term changes to the pituitarygonadal axis, neither testis weight nor the androgen-dependent weights of reproductive tract and perineal muscles were affected in adult males (Table 2). All female groups (regardless of neonatal treatment) received androgens as adults to enhance the size and staining properties of the neurones (Arnold, 1984).

In normal male rats, studies involving HRP injection have confirmed that the majority of SNB neurones (also termed dorsomedial neurones, e.g. Schrøder, 1980) innervate the perineal muscles bulbocavernosus and levator ani (the latter has also been described as a dorsal component of bulbocavernosus (Hayes, 1965; McKenna \& Nadelhaft, 1986) or an external anal sphincter (Cihák et al., 1967, 1970)). A minority of SNB neurones, and the small number of SNB neurones still present in adult females, innervate the anal sphincter (Schrøder, 1980; McKenna \& Nadelhaft, 
1986). In rats perineal muscles develop initially in both sexes but in females they involute either after birth (when the muscle has reach myotube formation stage) or at about 3 weeks after birth (when involution involves fully developed muscle fibres) (Cihák et al., 1970). No morphologically detectable perineal muscles occur in adult females. The persistence of thin contractile sheets has been argued from pudendal nerve stimulation studies (McKenna \& Nadelhaft, 1986), but without histological verification. Nor does androgen administration to adult female rats result in clearly detectable perineal muscles (Hayes, 1965). The present experiment confirms previous reports (Arnold, 1984) that perinatal androgen administration maintains the perineal muscles as well as the SNB neurones which innervate them. Both testosterone and dihydrotestosterone maintained perineal muscles, but in neither case were the muscles as large as in normal males; Davidson \& Payne (1989) have shown that the perineal muscles of perinatally androgen-treated female rats possess only a third or a half of the fibres found in the muscles of normal males. Oestradiol could not maintain perineal muscles, despite reports that these possess oestradiol receptors in the adult (e.g. Dubé et al., 1976). Moreover, the finding that oestradiol-treated females possess SNB neurones without their normal target musculature is at odds with the suggestion by Breedlove (1986) that hormones act on this system primarily by maintaining perineal muscles and that the effect on neurone survival is an indirect consequence. For the oestradiol-treated females in the present experiment, it is not clear what the SNB neurones are innervating, although muscles of the hind limb are a likely target.

The experiments performed here demonstrate that Albino Swiss rats resemble Sprague-Dawley rats in exhibiting sexual dimorphisms in SNB neurone numbers and in the presence or absence of the perineal muscles which are their normal targets. Furthermore, they are similar in their requirement for androgens during the perinatal period to maintain both neurones and muscles. However, the results suggest that there may be differences between strains in their specific hormone requirements and highlight the need to consider possible strain differences in other aspects of this developmental model.

This work was partly supported by summer vacation grants awarded to Miss P. A. Houston and Miss A. Henderson. We thank the Lord Fraser of Allander Trust, the Andrew and Mary Elizabeth Little Trust and the George Craig Trust Fund for their kind support.

\section{References}

Arnold, A.P. (1984) Androgen regulation of motor neuron size and number. Trends in Neuroscience 7 , $239-242$.

Arnold, A.P. \& Gorski, R.A. (1984) Gonadal steroid induction of structural sex differences in the central nervous system. Ann. Rev. Neurosci. 7, 413-442.

Bleier, R., Byne, W. \& Siggelkow, I. (1982) Cytoarchitectonic sexual dimorphisms of the medial preoptic and anterior hypothalamic areas in guinea pig, rat, hamster and mouse. J. comp. Neurol. 212, 118-130.

Breedlove, S.M. (1984) Steroid influences on the development and function of a neuromuscular system. Prog. Brain Res. 61, 147-170.

Breedlove, S.M. (1986) Absence of androgen accumulation by motoneurons of neonatal rats. Soc. Neurosci. Abstr. 12, 1220 , abstr.

Breedlove, S.M. \& Arnold, A.P. (1981) Sexually dimorphic motor nucleus in the rat lumbar spinal cord: response to adult hormone manipulation, absence in androgeninsensitive rats. Brain Res. 225, 297-307.

Breedlove, S.M. \& Arnold, A.P. (1983) Hormonal control of a developing neuromuscular system. II. Sensitive periods for the androgen induced masculinization of the rat spinal nucleus of the bulbocavernosus. $J$. Neurosci. 3, 424-432.

Breedlove, S.M., Jacobson, C.D., Gorski, R.A. \& Arnold, A.P. (1982) Masculinization of the female rat spinal cord following a single neonatal injection of testosterone propionate but not estradiol benzoate. Brain Res. 237, 173-181.

Brodie, A.M.H., Schwarzel, W.C., Shaikh, A.A. \& Brodie, H.J. (1977) The effect of an aromatase inhibitor, 4-hydroxy-4-androstene-3,17-dione, on estrogendependent processes in reproduction and breast cancer. Endocrinology.100, 1684-1695.

Cihák, R., Gutmann, E. \& Hanzliková, V. (1967) Morphologische, physiologische Merkmale, Entwicklung und Homologie des M. "Levator" ani der Ratte. Anat. Anz. 120, 492-506.

Cỉhák, R., Gutmann, E. \& Hanzliková, V. (1970) Involution and hormone-induced persistence of the M. sphincter (levator) ani in female rats. J. Anat. 106, 93-110.

Davidson, T. \& Payne, A.P. (1989) Perineal muscles and their motor neurons: the effects of perinatal hormone treatment. J. Anat. 167, 273. 
Dubé, J.Y., Lesage, R.\& Tremblay, R.R. (1976) Androgen and estrogen binding in rat skeletal and perineal muscles. Can. J. Biochem. 54, 50-55.

Forger, N.G.\& Breedlove, S.M. (1986) Sexual dimorphism in human and canine spinal cord: role of early androgen. Proc. natn. Acad. Sci. USA 83, 7527-7531.

Gorski, R.A., Harlan, R.E., Jacobson, C.D., Shryne, J.E. \& Southam, A.M. (1980) Evidence for the existence of a sexually dimorphic nucleus in the preoptic area of the rat. J. comp. Neurol. 193, 529-539.

Hall, D.S., Rasmussen, K.M. \& Breedlove, S.M. (1987) Early androgen and estrogen differentially affect adult morphology of sexually dimorphic spinal nucleus. Soc. Neurosci. Abstr. 13, 1519, abstr.

Hayes, K.J. (1965) The so-called "levator ani" of the rat. Acta endocr., Copenh. 48, 337-347.

Kurz, E.M., Sengelaub, D.R. \& Arnold, A.P. (1986) Morphology of rat spinal motoneurons with normal and hormonally altered specificity. Soc. Neurosci. Abstr. 12, 1218, abstr.

Liang, T. \& Heiss, C.E. (1981) Inhibition of $5 a$-reductase, receptor binding and nuclear uptake of androgens in the prostate by a 4-methyl-4-aza-steroid. J. biol. Chem. 256, 7998-8005.

Liang, T., Rasmusson, G.H. \& Brooks, J.R. (1983) Biochemical and biological studies with 4-aza-steroidal $5 \alpha$-reductase inhibitors. J. Steroid Biochem. 19, 385-390.

Marsh, D.A., Brodie, H.J., Garrett, W., Tsai-Morris, C-H. \& Brodie, A.M.H. (1985) Aromatase inhibitors. Synthesis and biological activity of androstenedione derivatives. $J$. med. Chem. 28, 788-795.

McKenna, K.E. \& Nadelhaft, I. (1986) The organization of the pudendal nerve in the male and female rat. $J$. comp. Neurol. 248, 532-549.

Nishizuka, M. \& Arai, Y. (1981) Sexual dimorphism in synaptic organization in the amygdala and its dependence on neonatal hormone environment. Brain Res. 212, 31-38.
Schroder, H.D. (1980) Organization of the motoneurons innervating the pelvic muscles of the male rat. $J$. comp. Neurol. 192, 567-587.

Segovia, S., Valencia, A., Cales, J.M. \& Guillamon, A. (1986) Effects of sex steroids on the development of two granule cell subpopulations in the rat accessory olfactory bulb. Devl Brain Res. 30, 283-286.

Sengelaub, D.R. (1989) Cell generation, migration, death and growth in neural systems mediating social behavior. In Advances in Comparative and Environmental Physiology. 3. Molecular and Cellular Basis of Social Behavior in Vertebrates, pp. 239-267. Ed. J. Balthazart. Springer-Verlag, Berlin.

Sengelaub, D.R., Nordeen, E.J., Nordeen, K.W. \& Arnold, A.P. (1989) Hormonal control of neuron number in sexually dimorphic spinal nuclei of the rat. III. Differential effects of the androgen dihydrotestosterone. J. comp. Neurol. 280, 637-644.

Tobet, S.A., Zahniser, D.J. \& Baum, M.J. (1986) Differentiation in male ferrets of a sexually dimorphic nucleus of the preoptic/anterior hypothalamic area requires prenatal estrogen. Neuroendocrinology 44, 299-308.

Wee, B.E.F. \& Clemens, L.G. (1986) Strain differences in morphology of the spinal nucleus of the bulbocavernosus (SNB) in mice. Soc. Neurosci. Abstr. 12, 1219 , abstr.

Wee, B.E.F. \& Clemens, L.G. (1987) Characteristics of the spinal nucleus of bulbocavernosus are influenced by genotype in the house mouse. Brain Res. 424, 305-310.

Venable, J.H. (1966) Morphology of the cells of normal, testosterone-deprived and testosterone-stimulated levator ani muscles. Am. J. Anat. 119, 271-302.

Received 28 October 1989 